\title{
Associations of pet ownership with biomarkers of ageing: population based cohort study
}

\author{
G David Batty, ${ }^{1}$ Paola Zaninotto, ${ }^{1}$ Richard G Watt, ${ }^{1}$ Steven Bell ${ }^{2}$
}

${ }^{1}$ Department of Epidemiology and Public Health, University

College, London, UK

${ }^{2}$ Department of Public Health and Primary Care, University of Cambridge, Cambridge, UK

Correspondence to: G D Batty david.batty@ucl.ac.uk

Additional material is published online only. To view please visit the journal online.

Cite this as: $B M J$ 2017;359:j5558 http://dx.doi.org/10.1136/bmj.j5558

Accepted: 24 November 2017

\section{ABSTRACT}

OBJECTIVE

To examine the prospective relation between animal companionship and biomarkers of ageing in older people.

DESIGN

Analyses of data from the English Longitudinal Study of Ageing, an ongoing, open, prospective cohort study initiated in 2002-03.

\section{SETTING}

Nationally representative study from England. PARTICIPANTS

8785 adults (55\% women) with a mean age of 67 years (SD 9) at pet ownership assessment in 2010-11 (wave 5).

\section{MAIN OUTCOME MEASURE}

Established biomarkers of ageing in the domains of physical, immunological, and psychological function, as assessed in 2012-13 (wave 6).

RESULTS

One third of study members reported pet ownership: 1619 (18\%) owned a dog, 1077 (12\%) a cat, and 274 (3\%) another animal. After adjustment for a range of covariates, there was no evidence of a clear association of any type of pet ownership with walking speed, lung function, chair rise time, grip strength, leg raises, balance, three markers of systemic inflammation, memory, or depressive symptoms.

\section{CONCLUSION}

In this population of older adults, the companionship of creatures great and small seems to essentially confer no relation with standard ageing phenotypes.

\section{Introduction}

The notion that animal companionship might be linked to human health can be traced to ancient writings and, with the first population based study conducted at least four decades ago, ${ }^{1}$ the specialty has a long research pedigree. This is particularly the case for the study of patient groups, with rather fewer investigations of the general population. ${ }^{2-4}$ That present day surveys indicate that around half of UK households own a

\section{WHAT IS ALREADY KNOWN ON THIS TOPIC}

Half of older people in the UK own a pet and $12 \%$ of older Australians report that animals are their predominant form of companionship

The relation of animal companionship, a potentially modifiable characteristic, with biomarkers of ageing in older people is largely unknown

\section{WHAT THIS STUDY ADDS}

Of 11 biomarkers of ageing, there was no evidence of a clear relation with pet ownership pet $^{5}$-reflecting secular increases over recent yearssuggests that interaction with animals is perceived as life enhancing.

There are persuasive prima facie reasons to anticipate that pet ownership may have both negative and positive health consequences. Deleterious impacts on human health could occur if owners delayed their own medical care in preference to pet welfare; grief and distress occurred after a companion animal's death ${ }^{6}$; or, most obviously, owners were attacked by their pet. ${ }^{7}$ The numerous potential zoonotic hazards that might accompany pet ownership have been described, but occurrences seem rare, at least in Western societies. ${ }^{89}$ Alternatively, psychological health may be improved by the perceived sense of companionship provided by pets. The increased physical exertion commensurate with dog ownership ${ }^{1011}$ may influence weight regulation and therefore cardiometabolic factors. Additionally, case reports in diagnostic medicine describe the ability of pet dogs to detect the early stages of an epileptic fit and even selected malignancies. ${ }^{8}$ These supposed benefits arising from human-animal relationships have led to ambitious calls for the comprehensive integration of human, animal, environmental, and ecosystem health. ${ }^{12}$

Although some empirical evidence links animal companionship with apparent protection against a series of important health outcomes in middle aged populations, including premature mortality, obesity, hypertension, and hyperlipidaemia, systematic reviews $^{13}$ and position statements ${ }^{3}$ suggest that these associations are not universal. Despite $12 \%$ of older Australians indicating that an animal was their predominant form of company, ${ }^{14}$ little is known about the impact of such companionship on physical and psychological biomarkers of ageing in older peoplefactors that are related to life expectancy, chronic disease, and disability. ${ }^{15}$ If there is a relation with ageing biomarkers, which may be anticipated given the described links with physical exertion and sense of companionship, the public health implications of animal ownership could be important.

The few studies in this area have almost exclusively utilised a cross-sectional design and focused on single, self reported biomarkers of ageing, particularly depression, which provide only a partial understanding of the health consequences of pet ownership and raise concerns of recall bias, particularly in older groups. Reverse causality may also be a problem, whereby decreased mobility in older age may be the reason for seeking animal companionship, rather than the reverse, and this may have led to the apparent deleterious relation of certain pets with poor health status, ${ }^{16}$ including suboptimal mental health ${ }^{17}$ in some 
studies of older people. Accordingly, we examined the prospective link between pet ownership and a selected range of objective biomarkers of ageing proposed for use in large scale population based studies of older people. ${ }^{15}$

\section{Methods}

\section{Study population}

The English Longitudinal Study of Ageing (ELSA) is an ongoing, open, prospective cohort study of a representative sample of men and women who, when recruited in 2002-03 (wave 1), were aged 50 or more and living in private households in England. ${ }^{18}$ Data have been collected biennially in the home using computer assisted personal interviews and self completion questionnaires, with additional nurse visits during alternate waves for the assessment of biomedical data. Comparison of the sociodemographic characteristics of participants against the profile in the national census indicates that the sample remains broadly representative of the English population. ${ }^{18}$

For the purposes of our analyses, the study baseline is wave 5 (2010-11), when inquiries about pet ownership were first introduced into the study. Cohort members were asked "Do you keep any household pets inside your house/flat?," followed by items about specific pets (dog, cat, bird, other furry pet, or "other" type of pet). ${ }^{19}$ We collapsed the last three groups owing to a low prevalence of ownership.

\section{Physical biomarkers}

We utilised follow-up data on biomarkers of ageing as collected at wave 6 (2012-13), around two years after assessment of pet ownership. ${ }^{20}$ A walking speed test was administered to participants aged 60 years or more, using walking aids if required, and was based on the time taken to walk a distance of $2.4 \mathrm{~m}$ and back. ${ }^{21}$ Measures of physical strength included hand grip (for upper body) and the timed chair stand test (for lower body). ${ }^{22} \mathrm{~A}$ hand held dynamometer was used to measure hand grip strength $(\mathrm{kg})$ in the dominant hand. In the chair stand test, the time required to rise from a chair to a full standing position on five occasions with arms folded across the chest was recorded; a slower time reflected poorer function.

Static balance was evaluated in three separate and progressively more difficult tests. ${ }^{23} 24$ For the side-byside and semi-tandem stand, we gave participants who could hold their position for 10 seconds a score of 1 for each test outcome. For the full tandem stand, study members able to hold the position for 3-10 seconds scored 1 point, with those able to hold the position for more than 10 seconds allocated 2 points. A final score of 3 or less out of a possible 5 denoted impaired balance. ${ }^{23}$ A leg raise assessment was administered to all participants aged less than 70 years who successfully completed the side-by-side balance test: with their eyes open, study members were asked to raise one leg for 30 seconds from a standing position. Finally, forced expiratory volume in one second was ascertained using a standard handheld Vitalograph spirometer. $^{25}$

\section{Immunological biomarkers}

A blood sample was drawn from consenting respondents and analysed for inflammatory markers, including acute phase reactants (high sensitivity $C$ reactive protein, white blood cell count) and coagulation products (fibrinogen). ${ }^{26} \quad 27$ The technicalities of the blood analyses, and the quality assessment of the measurement laboratory, have been described in detail elsewhere. ${ }^{28}$

\section{Psychological biomarkers}

Memory was measured using a word list learning test in which 10 words were presented orally to participants who were then asked to recall as many as possible immediately after reading, and again after a five minute delay during which they completed other survey items. ${ }^{29}{ }^{30}$ Scores on both tests were totalled (range 0-20). Depressive symptoms were assessed at baseline and follow-up using the eight item Centre of Epidemiological Studies Depression scale. ${ }^{31}$ We used a score of 3 or more to define "caseness,"32 33 a threshold that has been validated against standardised psychiatric interviews in older populations. $^{31}$

\section{Confounding and mediating factors}

Other data collected at baseline (wave 5), simultaneous with the assessment of pet ownership, were used to derive covariates. Height and weight were measured directly using standard procedures; body mass index was computed using the conventional formulas. ${ }^{23}$ ${ }^{34}$ The remaining data were self reported. Cigarette smoking was classified as current, former, or never. An assessment of physical activity was based on items about engagement in activities of vigorous, moderate, or mild intensity, from which a 5 point scale was derived (a lower value denoting more sedentary behaviour). Alcohol intake was based on units consumed each week. ${ }^{35}$ Our socioeconomic variable was total net nonpension household wealth as based on an estimation of the assets of study members and their partners, including, where applicable, properties, businesses, other assets, and any form of investments or savings (except for pension savings), less debts owed by them. ${ }^{36}$ ${ }^{37}$ We created an index of social isolation by assigning scores based on responses to questions about marital status/cohabitation, contact with family or friends, and participation in social groups. ${ }^{38} \mathrm{~A}$ higher score indicated less social contact. The degree of loneliness was ascertained using the UCLA loneliness scale (revised) ${ }^{39}$; a higher score reflecting greater loneliness. Participants were also asked to rate their health on a 5 point scale, with a higher score being less favourable. In regression analyses, we regarded wealth, self reported health, smoking status, and alcohol consumption as confounding factors, and social isolation, loneliness, physical activity, and body mass index as mediating factors. In further post hoc analyses, we also controlled 


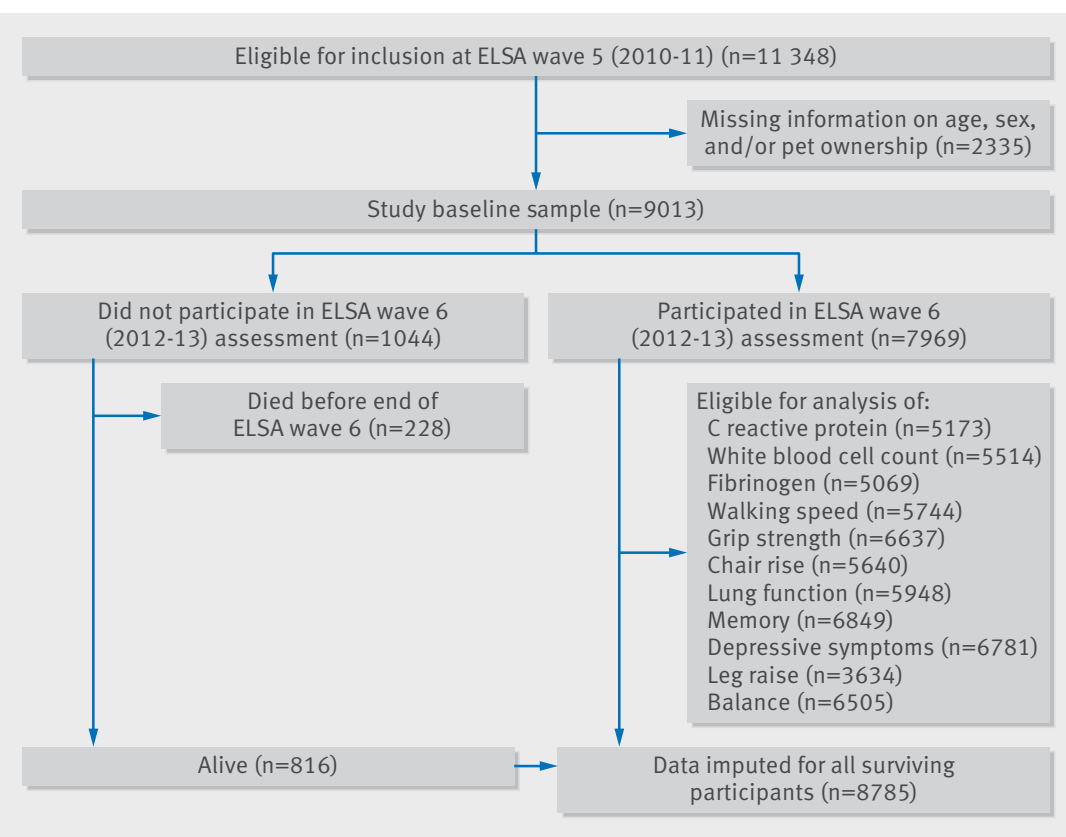

Fig 1 | Flow of participants through phases of data collection and imputation

for baseline measurement of the outcome of interest as ascertained at wave 4 (2008-09).

\section{Patient involvement}

This paper is based on a prospective cohort study in which we recruited members of the general population and collected data on an array of potential risk factors and health outcomes. As a study of the general population, patients were not involved in constructing the present research question, the outcome measures, nor the design, recruitment, or implementation of the study. No patients were asked to advise on interpretation or writing up of results. There are no plans to disseminate the results of this specific research to study participants. The study data are freely available to the research community.

\section{Data imputation and statistical analyses}

Given loss to follow-up that is inevitable in a cohort study, we imputed missing data. This involved the generation of 10 datasets, resulting in a sample of 8785 participants for our main analyses (fig 1). We ascertained if the imputations were plausible by comparing plots of the distribution of observed and imputed values. Effect estimates were computed separately for each of the 10 datasets and then combined using the Rubin method. ${ }^{40}$ Results using this approach were similar to those based on analyses of non-missing datasets, so we elected to report results from the imputed dataset for the greater precision it provides. We log transformed all ageing outcomes that were not normally distributed-in practice, the inflammatory markers of C-reactive protein, white blood cell count, and fibrinogen. ${ }^{41} \beta$ coefficients with accompanying 95\% confidence intervals were estimated using a series of linear regression models; for the log transformed data, these coefficients and confidence intervals were multiplied by 100 and expressed as percentage differences. ${ }^{42}$ We used modified Poisson regression ${ }^{43}$ to estimate relative risks for binary ageing phenotypes. All effect estimates were adjusted for a series of covariates. We adopted a Bonferroni corrected $\mathrm{P}$ value threshold of $<0.0045$ (0.05 divided by 11 outcomes) as providing strong evidence of differences in biomarkers between the pet ownership groups. All statistical analyses were conducted using Stata version 15.1.

\section{Results}

After imputation, in our analytical sample of 8785 ( 4863 women; 55\%) the mean age at baseline was 67 years (SD 9), with mean age at follow-up around two years later of 69 (SD 8) years. One third of study members reported owning any type of animal: 1619 (18\%) a dog, 1077 (12\%) a cat, and 274 (3\%) other. Participants' baseline characteristics did not differ consistently according to type of animal owned, and where differences were evident they were typically modest (table 1). Thus, compared with participants who did not own a pet, those who did were moderately younger and less likely to be physically inactive. Dog owners were more likely to be lonely and be in poorer health. Compared with participants who did not report owning a pet, in those who did, smoking was marginally more common.

For the longitudinal relations between pet ownership and the ageing biomarkers, results are divided according to theme of the outcome: physical function (fig 2), immune function (fig 3), and psychological function (fig 4). After adjustment for multiple covariates, there were no strong relations between different types of pet ownership

\begin{tabular}{|c|c|c|c|c|c|}
\hline Characteristics & No pet $(n=5815)$ & $\operatorname{Dog}(n=1619)$ & Cat $(n=1077)$ & Other $(n=274)$ & Full cohort $(n=8785)$ \\
\hline Mean (SD) age (years) & $69(9)$ & $65(8)$ & $65(8)$ & $64(8)$ & $67(9)$ \\
\hline Women & $3199(55)$ & $900(56)$ & $617(57)$ & $147(54)$ & $4863(55)$ \\
\hline Lowest wealth fifth & $915(16)$ & $324(20)$ & $143(13)$ & $57(21)$ & $1439(16)$ \\
\hline Socially isolated & $1292(22)$ & $377(23)$ & $229(21)$ & $77(28)$ & $1975(22)$ \\
\hline Lonely & $1228(21)$ & $421(26)$ & $227(21)$ & $53(19)$ & $1929(22)$ \\
\hline Poor self rated health & $1610(28)$ & $509(31)$ & $269(25)$ & $88(32)$ & $2476(28)$ \\
\hline Mean (SD) body mass index & $28(5)$ & $29(5)$ & $28(5)$ & $29(5)$ & $28(5)$ \\
\hline Physically inactive & 1105 (19) & $240(15)$ & $154(14)$ & $49(18)$ & $1548(18)$ \\
\hline Current smoker & $669(12)$ & $314(19)$ & $172(16)$ & $40(15)$ & $1195(14)$ \\
\hline Median (interquartile range) alcohol intake (units/wk) & $3(0-9)$ & $3(0-10)$ & $3(0-10)$ & $3(0-10)$ & $3(0-9)$ \\
\hline
\end{tabular}




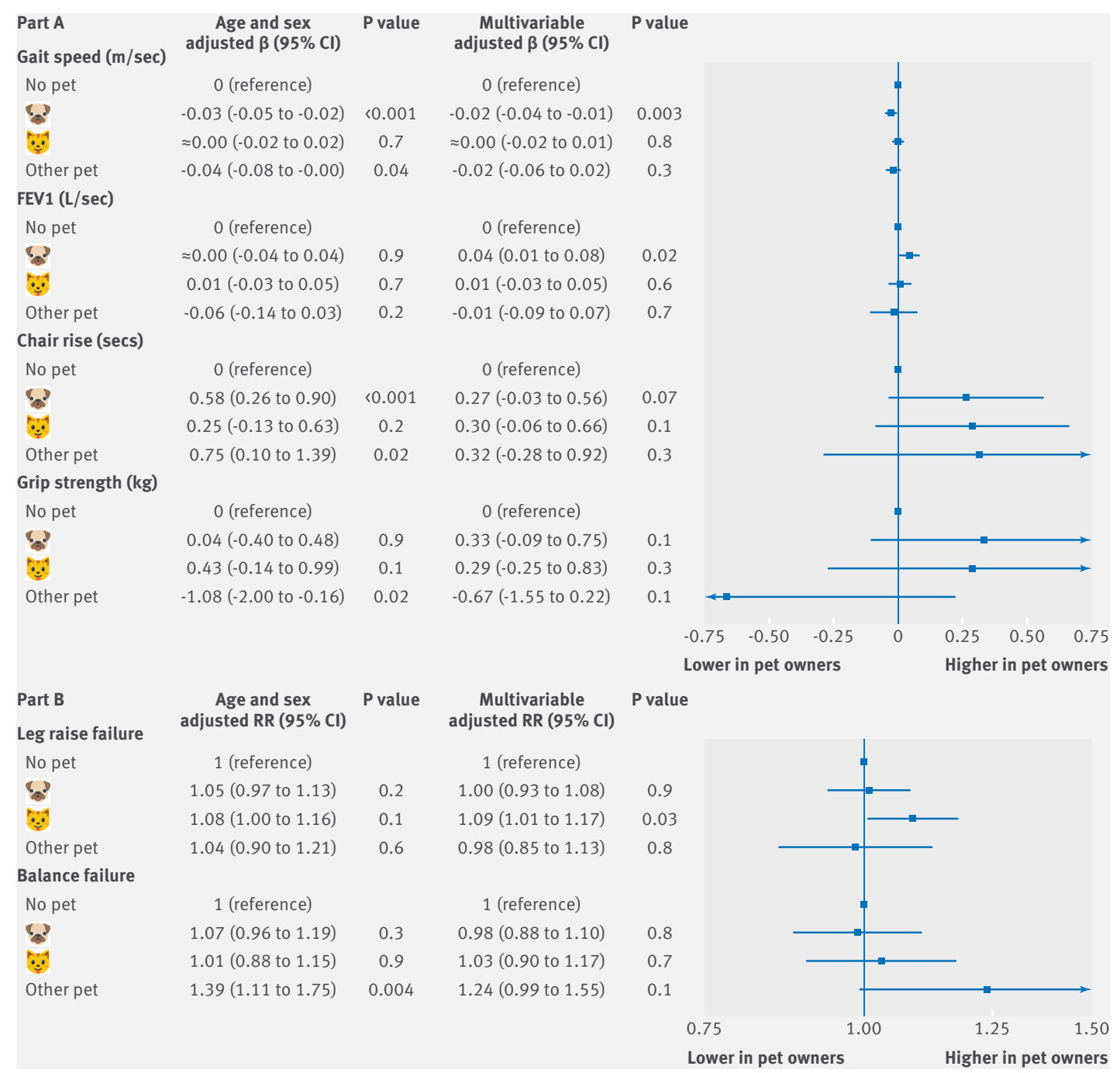

Fig 2 | $\beta$ coefficients (top panel) and relative risks (bottom panel) for relation of pet ownership with ageing biomarkers: physical functioning $(n=8785)$. Multivariable adjustment is for age, sex, wealth, social isolation, loneliness, self rated health, physical activity, cigarette smoking, alcohol intake, and body mass index

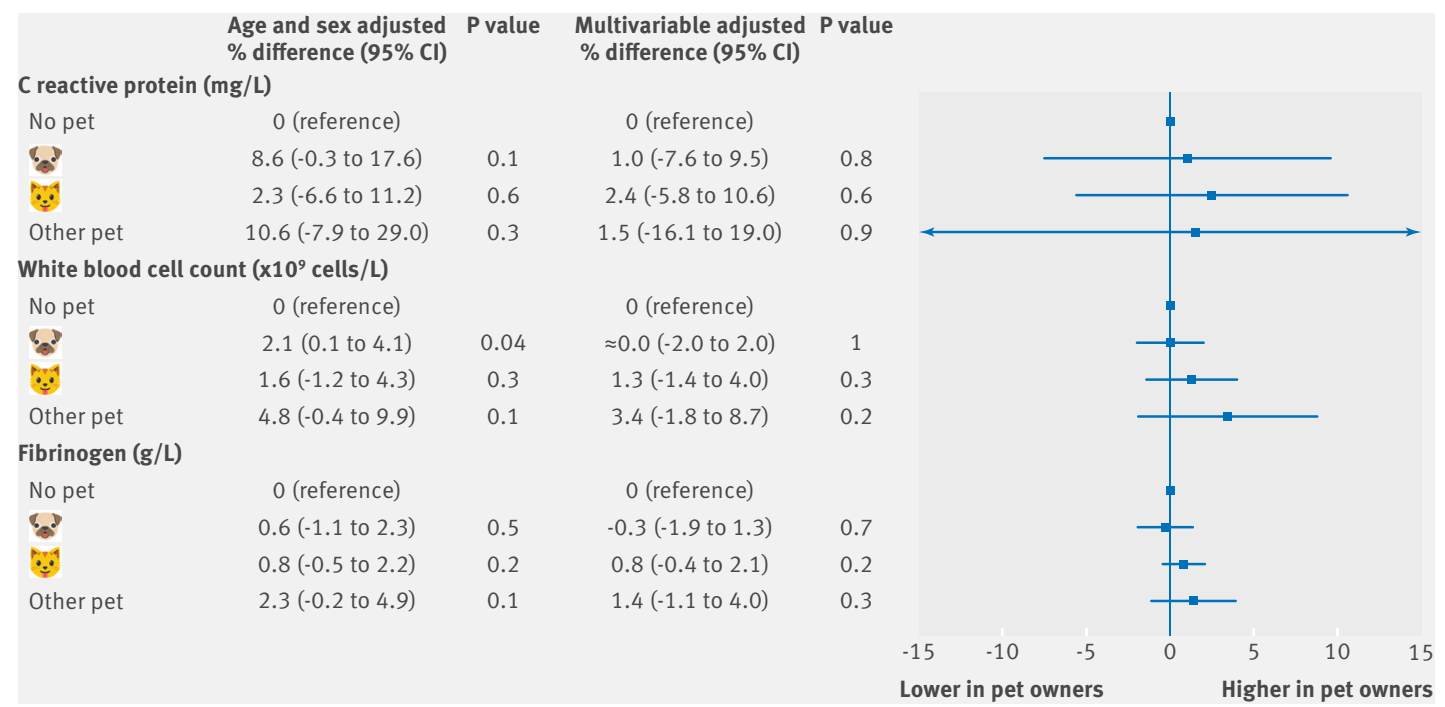

Fig 3 | Percentage differences for relation of pet ownership with ageing biomarkers: immune functioning $(n=8785)$. Multivariable adjustment is for age, sex, wealth, social isolation, loneliness, self rated health, physical activity, cigarette smoking, alcohol intake, and body mass index 


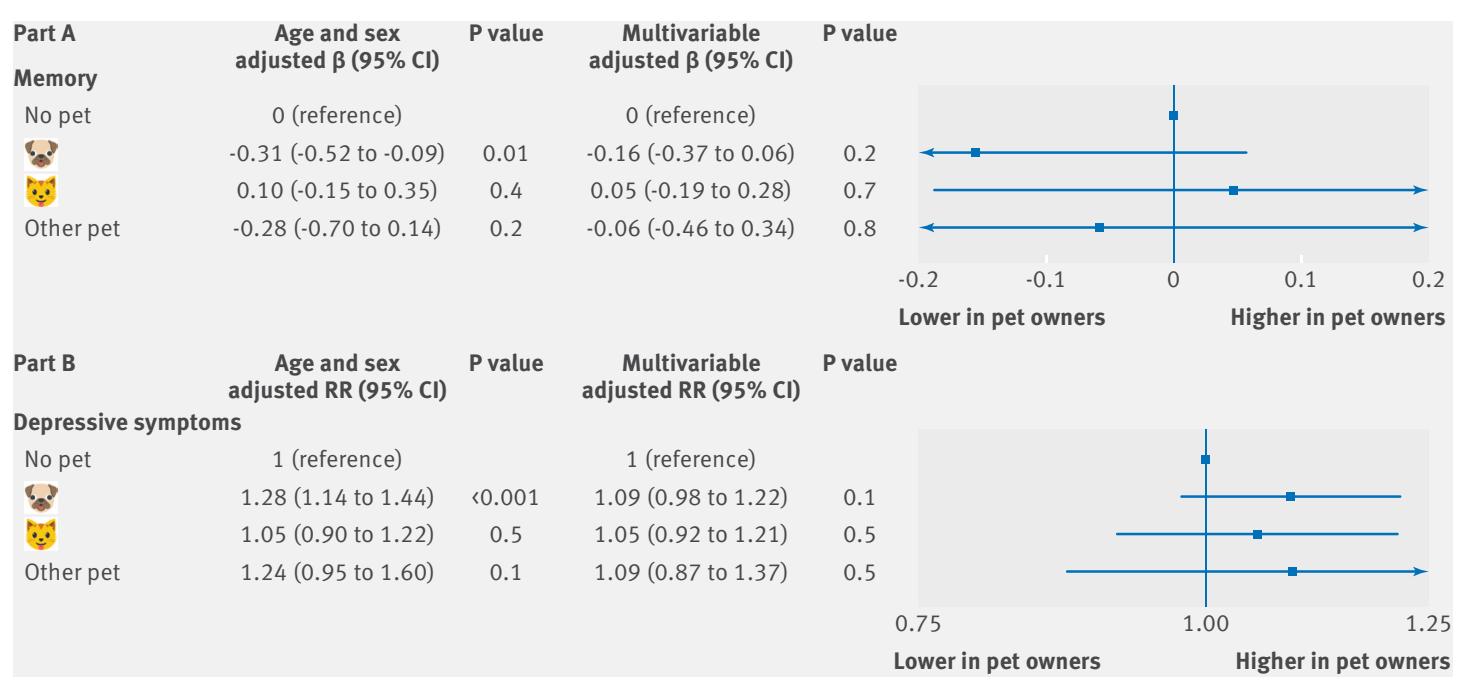

Fig 4 | $\beta$ coefficients (top panel) and relative risks (bottom panel) for relation of pet ownership with biomarkers of ageing: psychological functioning $(n=8785)$. Multivariable adjustment is for age, sex, wealth, social isolation, loneliness, self rated health, physical activity, cigarette smoking, alcohol intake, and body mass index

and the various physical biomarkers of ageing, and statistical significance at conventional levels was rarely apparent. Compared with participants who did not report pet ownership, dog companionship was associated with somewhat slower walking speed and a longer time to rise from a chair; conversely, dog ownership was also related to a slightly higher pulmonary function. Cat owners were more likely to fail the leg raise test than people in the other pet ownership groups. Pet ownership was essentially unrelated to our three immunological markers of $\mathrm{C}$ reactive protein, white blood cell count, and fibrinogen. There was no apparent relation between ownership of any type of pet and cognitive function or symptoms of depression.

We carried out some planned subgroup analyses. To make the impact of controlling for groups of variables transparent, we disaggregated the multivariable model into confounding and potential mediating factors (supplementary figures 1-3). We also examined if the relation of pet ownership with ageing biomarkers was modified by the owner's sex (supplementary figures 4-6); we explored the association of pet ownership with additional health indices that are not considered to be markers of ageing (supplementary figure 7); and, finally, we tested the impact of adjustment of the baseline (wave 4) assessment of each ageing biomarker (supplementary figures 8-11). In summary, in separate analyses of men and women, similar observations were made to those apparent in the full cohort; links between pet ownership and other health indices were few, and where they did exist were again of modest magnitude; and taking into account earlier measurement of the outcome of interest did not materially change our general finding of null results.

\section{Discussion}

Of the widely used biomarkers of ageing we prospectively related to pet ownership in this study, there was no clear evidence of association. Some possible exceptions were walking speed and chair rise time, which were both less favourable among people reporting dog companionship, although the magnitude of these effects was undoubtedly low.

\section{Strengths and limitations of this study}

The present study has some strengths, which include its size; the analyses of the prospective relation between pet ownership and health, which reduces concerns about reverse causality; and the range of covariates captured, which allowed us to explore alternative explanations for the associations under investigation.

Our study does of course have its limitations. Firstly, to date, pet ownership was only measured on one occasion. With evidence suggesting that this characteristic is time varying, ${ }^{44}$ repeat assessment would provide more accuracy. The same concern could be applied to almost any exposure in epidemiology, however, including those that have subsequently become known causal risk factors for chronic disease (eg, smoking and lung cancer, raised blood pressure and stroke). It is likely that this variation over time in pet ownership would lead to an underestimation of the true effects. ${ }^{45}$ Secondly, it may also be that pet ownership has an impact on health outcomes that were not included herein, such as biomarkers of psychological stress (eg, cortisol). Thirdly, we had no information on who was responsible for the care of the pet-study members may report pet ownership, but they may not be the primary caregiver and therefore perhaps not experience the potential health benefits. We also did not have specific details of ownership which, in addition to caretaking, include frequency of interaction, and, in the case of dogs, the care of which may require higher levels of physical exertion, age and breed of the animal, duration of ownership, and, where applicable, time spent walking. ${ }^{46}$ Finally, as our study is observational, there is the perennial concern of 
confounding by unknown factors. Randomised trials of the health consequences of pet ownership in an older population could be conducted, although blinding of participants and investigators would be impossible and the generalisability of findings from what are often highly select participants in trials is moot.

\section{Comparison with other studies}

With the exception of mental health outcomes, we are unaware of any observational studies that have examined the links between pet ownership and biomarkers of ageing. For depression, evidence from some cross sectional studies suggests that people who report owning animals experience a higher prevalence of such symptoms, ${ }^{14}$ whereas in a one year follow-up of a small group of older, community dwelling Canadians, animal companionship showed no relation with later psychological health ascertained using a non-standard questionnaire. ${ }^{47}$ A small, quasiintervention study comprising people with multiple sclerosis found an apparent improvement in walking speed after utilisation of a service dog. ${ }^{48}$

\section{Conclusion}

In the present study, the companionship of creatures great and small seems to confer essentially no relation with standard physical and psychological biomarkers of ageing.

The English Longitudinal Study of Ageing was developed by a team of researchers based at University College London, the Institute for Fiscal Studies, and the National Centre for Social Research, UK.

Contributors: GDB conceived and designed the study, prepared an analytical plan, and wrote the manuscript. SB prepared an analytical plan and analysed all data. PZ and SB built the dataset. All authors commented on earlier versions of the manuscript. GDB and SB will act as guarantors.

Funding: This study was funded by the US National Institute on Ageing, and a consortium of UK government departments coordinated by the Economic and Social Research Council. GDB is supported by the UK Medical Research Council (MRC; MR/P023444/1) and the US National Institute on Ageing (1R56AG052519-01; 1R01AG05251901A1). The views expressed herein by the authors are independent of all funding agencies.

Competing interests: All authors have completed the ICMJE uniform disclosure form at www.icmje.org/coi_disclosure.pdf and declare: no support from any organisation for the submitted work; no financial relationships with any organisations that might have an interest in the submitted work in the previous three years; no other relationships or activities that could appear to have influenced the submitted work. SB is the very proud owner of two naughty tortie Persian cats but, sadly, zero pugs. GDB, a vicarious rabbit owner as a child, does not currently own an animal but his home does have a minor moth infestation. PZ yearns for the parrots of her youth, Romeo and Juliet, but present living circumstances thankfully preclude such tragic romantic dalliances. RGW has a longstanding affection for dogs, not cats, and is the fond owner of a magnificent labrador, Tilda, named after the actress, not the Irish sister study to ELSA.

Ethical approval: Data collection for this study was approved by the London Multicentre Research Ethics Committee.

Data sharing: The data described herein are curated by the UK Data Archive at the University of Essex and can be downloaded free of charge for non-commercial purposes from the Economic and Social Data Service (www.esds.ac.uk/findingData/hseTitles.asp). Syntax for our analyses are available from SB.

Transparency: The lead author (GDB) affirms that the manuscript is an honest, accurate, and transparent account of the study being reported, and that no important aspects of the study have been omitted. and that any discrepancies from the study as planned (and, if relevant, registered) have been explained.
This is an Open Access article distributed in accordance with the Creative Commons Attribution Non Commercial (CC BY-NC 4.0) license, which permits others to distribute, remix, adapt, build upon this work non-commercially, and license their derivative works on different terms, provided the original work is properly cited and the use is noncommercial. See: http://creativecommons.org/licenses/by-nc/4.0/.

1 Friedmann E, Katcher AH, Lynch JJ, Thomas SA. Animal companions and one-year survival of patients after discharge from a coronary care unit. Public Health Rep 1980;95:307-12.

2 Mubanga M, Byberg L, Nowak C. Dog ownership and the risk of cardiovascular disease and death - a nationwide cohort study. Sci Rep 2017;7:15821. doi:10.1038/s41598-017-16118-6

3 Levine GN, Allen K, Braun LT. American Heart Association Council on Clinical Cardiology Council on Cardiovascular and Stroke Nursing. Pet ownership and cardiovascular risk: a scientific statement from the American Heart Association. Circulation 2013;127:2353-63. doi:10.1161/CIR.0b013e31829201e1

4 Batty GD, Bell S. Animal companionship and risk of suicide. Epidemiology 2017; (forthcoming).

5 Murray JK, Gruffydd-Jones TJ, Roberts MA, Browne WJ. Assessing changes in the UK pet cat and dog populations: numbers and household ownership. Vet Rec 2015;177:259. doi:10.1136/ vr.103223

6 Adams $\mathrm{CL}$, Bonnett $\mathrm{BN}$, Meek AH. Predictors of owner response to companion animal death in 177 clients from 14 practices in Ontario. J Am Vet Med Assoc 2000;217:1303-9. doi:10.2460/ javma.2000.217.1303

7 McNicholas J, Gilbey A, Rennie A, Ahmedzai S, Dono JA Ormerod E. Pet ownership and human health: a brief review of evidence and issues. BMJ 2005;331:1252-4. doi:10.1136/ bmj.331.7527.1252

8 Mayon-White R. Pets--pleasures and problems. BMJ 2005;331: 1254-5. doi:10.1136/bmj.331.7527.1254

9 Stull JW, Brophy J, Weese JS. Reducing the risk of pet-associated zoonotic infections. CMAl 2015;187:736-43. doi:10.1503/ cmaj. 141020

10 Christian H, Bauman A, Epping IN. Encouraging dog walking for health promotion and disease prevention. Am J Lifestyle Med 2016; 17 Apr 1559827616643686

11 Thorpe RJ Jr, Simonsick EM, Brach JS. Health, Aging and Body Composition Study. Dog ownership, walking behavior, and maintained mobility in late life. J Am Geriatr Soc 2006;54:1419-24. doi:10.1111/j.1532-5415.2006.00856.x

12 Rock M, Buntain BJ, Hatfield JM, Hallgrímsson B. Animal-human connections, "one health," and the syndemic approach to prevention. Soc Sci Med 2009;68:991-5. doi:10.1016/j. socscimed.2008.12.047

13 Cherniack EP, Cherniack AR. The benefit of pets and animal-assisted therapy to the health of older individuals. Curr Gerontol Geriatr Res 2014; 2014:623203.

14 Parslow RA, Jorm AF, Christensen H, Rodgers B, Jacomb P. Pet ownership and health in older adults: findings from a survey of 2,55 community-based Australians aged 60-64. Gerontology 2005;51: 40-7. doi:10.1159/000081433

15 Lara J, Cooper R, Nissan J. A proposed panel of biomarkers of healthy ageing. BMC Med 2015;13:222. doi:10.1186/s12916015-0470-9

16 Enmarker I, Hellzén O, Ekker K, Berg AG. Health in olde cat and dog owners: The Nord-Trondelag Health Study (HUNT)-3 study. Scand J Public Health 2012;40:718-24. doi:10.1177/1403494812465031

17 Enmarker I, Hellzén O, Ekker K, Berg AG. Depression in older cat and dog owners: the Nord-Trøndelag Health Study (HUNT)-3. Aging Ment Health 2015;19:347-52. doi:10.1080/13607863.2014.933310

18 Steptoe A, Breeze E, Banks J, Nazroo J. Cohort profile: the English longitudinal study of ageing. Int J Epidemiol 2013;42:1640-8. doi:10.1093/ije/dys168

19 Pikhartova J, Bowling A, Victor C. Does owning a pet protect older people against loneliness? BMC Geriatr 2014;14:106 doi:10.1186/1471-2318-14-106

20 Batty GD, Zaninotto P. Exposure to passive smoking and impairment in physical function in older people. Epidemiology 2017; (forthcoming). doi:10.1097/EDE.0000000000000784

21 Gale CR, Allerhand M, Sayer AA, Cooper C, Deary II. The dynamic relationship between cognitive function and walking speed: the English Longitudinal Study of Ageing. Age (Dordr) 2014;36:9682. doi:10.1007/s11357-014-9682-8

22 Hamer M, Molloy G). Association of C-reactive protein and muscle strength in the English Longitudinal Study of Ageing. Age (Dordr) 2009;31:171-7. doi:10.1007/s11357-009-9097-0

23 Stevens KN, Lang IA, Guralnik IM, Melzer D. Epidemiology of balance and dizziness in a national population: findings from the English Longitudinal Study of Ageing. Age Ageing 2008;37:300-5. doi:10.1093/ageing/afn019 
24 Guralnik JM, Simonsick EM, Ferrucci L. A short physical performance battery assessing lower extremity function: association with self-reported disability and prediction of mortality and nursing home admission. J Gerontol 1994;49:M85-94. doi:10.1093/ geronj/49.2.M85

25 Yohannes AM, Tampubolon G. Changes in lung function in older people from the English Longitudinal Study of Ageing. Expert Rev Respir Med 2014;8:515-21. doi:10.1586/17476348.2014. 919226

26 Stringhini S, Zaninotto P, Kumari M, Kivimäki M, Batty GD. Life course socioeconomic status and type 2 diabetes: the role of chronic inflammation in the English Longitudinal Study of Ageing. Sci Rep 2016;6:24780. doi:10.1038/srep24780

27 White J, Kivimäki M, Jokela M, Batty GD. Association of inflammation with specific symptoms of depression in a general population of older people: The English Longitudinal Study of Ageing. Brain Behav Immun 2017;61:27-30. doi:10.1016/j.bbi.2016.08.012

28 Craig R, Deverill C, Pickering K. Quality control of blood, saliva and urine analytes. In: Spronston K, Mindell J, eds. Health Survey for England 2004, Methodology and Documentation Vol 2. The Information Centre 2006

29 Batty GD, Deary II, Zaninotto P. Association of Cognitive Function With Cause-Specific Mortality in Middle and Older Age: Follow-up of Participants in the English Longitudinal Study of Ageing. Am J Epidemiol 2016;183:183-90. doi:10.1093/aje/kwv139

30 Gale CR, Deary IJ, Wardle J, Zaninotto P, Batty GD. Cognitive ability and personality as predictors of participation in a national colorectal cancer screening programme: the English Longitudinal Study of Ageing. I Epidemiol Community Health 2015;69:530-5. doi:10.1136/jech-2014-204888

31 Turvey CL, Wallace RB, Herzog R. A revised CES-D measure of depressive symptoms and a DSM-based measure of major depressive episodes in the elderly. Int Psychogeriatr 1999;11: 139-48. doi:10.1017/S1041610299005694

32 White J, Zaninotto P, Walters K. Duration of depressive symptoms and mortality risk: the English Longitudinal Study of Ageing (ELSA). Br J Psychiatry 2016;208:337-42. doi:10.1192/bjp.bp.114.155333

33 White J, Zaninotto P, Walters K. Severity of depressive symptoms as a predictor of mortality: the English longitudinal study of ageing. Psychol Med 2015;45:2771-9. doi:10.1017 S0033291715000732

34 Bell JA, Kivimaki M, Batty GD, Hamer M. Metabolically healthy obesity: what is the role of sedentary behaviour? Prev Med 2014:62:35-7. doi:10.1016/j.ypmed.2014.01.028

35 Britton A, Ben-Shlomo Y, Benzeval M, Kuh D, Bell S. Life course trajectories of alcohol consumption in the United Kingdom using longitudinal data from nine cohort studies. BMC Med 2015;13:47. doi:10.1186/s12916-015-0273-z
36 Stringhini S, Zaninotto P, Kumari M, Kivimäki M, Batty GD. Life course socioeconomic status and type 2 diabetes: the role of chronic inflammation in the English Longitudinal Study of Ageing. Sci Rep 2016;6:24780. doi:10.1038/srep24780

37 Stringhini S, Zaninotto P, Kumari M, Kivimäki M, Lassale C, Batty GD. Socio-economic trajectories and cardiovascular disease mortality in older people: the English Longitudinal Study of Ageing. Int J Epidemiol 2017; (forthcoming). doi:10.1093/ije/dyx106

38 Steptoe A, Shankar A, Demakakos P, Wardle J. Social isolation, loneliness, and all-cause mortality in older men and women. Proc Natl Acad Sci U S A 2013;110:5797-801. doi:10.1073/ pnas.1219686110

39 Hughes ME, Waite LJ, Hawkley LC, Cacioppo JT. A Short Scale for Measuring Loneliness in Large Surveys: Results From Two Population-Based Studies. Res Aging 2004;26:655-72. doi:10.1177/0164027504268574

40 Rubin D. Multiple imputation for nonresponse in surveys. Wiley, 1987. doi:10.1002/9780470316696

41 Sedgwick P. Log transformation of data. BMJ 2012;345:e6727. doi:10.1136/bmj.e6727

42 Cole TJ, Altman DG. Statistics Notes: Percentage differences, symmetry, and natural logarithms. BMJ 2017;358:j3683. doi:10.1136/bmj.j3683

43 Zou G. A modified poisson regression approach to prospective studies with binary data. Am J Epidemiol 2004;159:702-6. doi:10.1093/aje/kwh090

44 Cutt HE, Knuiman MW, Giles-Corti B. Does getting a dog increase recreational walking? Int J Behav Nutr Phys Act 2008;5:17. doi:10.1186/1479-5868-5-17

45 Clarke R, Shipley M, Lewington S. Underestimation of risk associations due to regression dilution in long-term followup of prospective studies. Am J Epidemiol 1999;150:341-53. doi:10.1093/oxfordjournals.aje.a010013

46 Ding D, Bauman AE, Sherrington C, McGreevy PD, Edwards KM Stamatakis E. Dog ownership and mortality outcomes in England: A pooled longitudinal analysis of six population-based cohorts. Am J Prev Med 2017; (forthcoming)

47 Raina P, Waltner-Toews D, Bonnett B, Woodward C, Abernathy T. Influence of companion animals on the physical and psychological health of older people: an analysis of a one-year longitudinal study. J Am Geriatr Soc 1999;47:323-9. doi:10.1111/j.1532-5415.1999. tb02996.x

48 Fjeldstad C, Pardo G. Immediate Effect of a Service Dog on Walking Speed in Individuals with Multiple Sclerosis and Gait Dysfunction: A Pilot Study. Int J MS Care 2017;19:40-1. doi:10.7224/15372073.2015-089

Supplementary information: eFigures 1-11 